\title{
Un puente (levadizo) entre el Marxismo y Pierre Bourdieu
}

\section{A drawbridge between Marxism and Pierre Bourdieu}

Juan Francisco Di Meglio dimeglio.juan@gmail.com

http://orcid.org/0000-0002-4649-1146

Laboratorio de Estudios en Cultura y Sociedad; Facultad de

Trabajo Social; Universidad Nacional de La Plata (Argentina)

\section{Resumen}

El académico inglés Michael Burawoy en su libro O marxismo encontra Bourdieu vuelve sobre autores identificados en la corriente marxista estableciendo, a decir del autor, "diálogos imaginarios" entre cada uno de ellos y Pierre Bourdieu, probablemente el sociólogo más influyente y reconocido del siglo XX, a los fines de interpelar su producción teórica desde el marxismo, paradigma en el cual Burawoy se inscribe.

Palabras clave: Marxismo; Bourdieu; diálogos.

\section{Abstract}

The English scholar Michael Burawoy in his book O Marxism find Bourdieu returns on authors identified in the Marxist current establishing, according to the author, "imaginary dialogues" between each of them and Pierre Bourdieu, probably the most influential and recognized sociologist of the $\mathrm{XX}$ century, for the purposes of questioning its theoretical production from Marxism, paradigm in which Burawoy is inscribed. 
Keywords: Marxism; Bourdieu; dialogs.

Michael Burawoy propone, a través de una serie de "diálogos imaginarios", responder una pregunta central: ¿Cuáles son las similitudes y diferencias entre el trabajo de Pierre Bourdieu y el marxismo? El libro es la materialización de una serie de cursos, traducidos al portugués por Fernando Rogério Jardim bajo la dirección del profesor Ruy Braga, que el autor dio en el Harvens Center for Social Justice de la Universidad de Wisconsin.

En el libro se recorren diferentes conceptos de Bourdieu, revisitados desde autores como Marx, Gramsci, Fanon, de Beauvoir y Wright Mills. Además, el autor expone algunas reflexiones derivadas de sus propias investigaciones empíricas, poniéndolas en comparación con Bourdieu y con la teoría marxista.

Desde la introducción, Michael Burawoy deja en claro que los diálogos que propone son hipotéticos, realizados en base a algunos de los textos de cada pensador con la finalidad de realizar una conversación entre Bourdieu y el marxismo.

El análisis que Burawoy propone tiene un hilo conductor con foco en dos puntos centrales de la obra de Bourdieu. Por un lado, sus planteos en torno al necesario distanciamiento entre la sociología académica y el mundo social; y por otro, en develar las formas de explotación que recaen sobre las clases dominadas, como clave del modo de funcionamiento del sistema capitalista y eje de comprensión necesario para el inicio de un proceso de transformación social.

En el primer capítulo del libro toma a Marx y Engels, enfatiza en las convergencias y divergencias entre ellos con Bourdieu, mostrando como en la obra del francés se sale de la sucesión histórica de campos económicos que planteaba Marx, para mirar y estudiar desde más ópticas a las superestructuras sociales, con un análisis estructural-funcional en torno a la coexistencia simultánea de diversos campos. En torno a las convergencias, Burawoy deja en claro que Bourdieu se acerca a Marx desde su crítica a la separación del "mundo de las ideas" de la praxis humana, base para la división social del trabajo. Otro punto de encuentro entre los autores radica en su iniciativa por desmenuzar, de manera crítica, la forma en la que cada sociedad produce sus ideas dominantes. En tal sentido, es que Bourdieu toma aportes del famoso trabajo de Marx y Engels, La Ideología Alemana para buscar clarificar la forma en que la cultura, su consumo y transmisión, esconde formas de dominación de una clase sobre otra. 
A continuación, tenemos el diálogo entre Bourdieu y Gramsci, donde Burawoy muestra algunos puntos de encuentro: ambos criticaron el determinismo histórico de Marx; desenvolvieron concepciones complejas en torno a las luchas de clase; tanto uno como el otro darán poca importancia a la economía y centrarán sus análisis en sus efectos, mirando los aspectos sociales, que Gramsci llamó superestructuras del capitalismo, y Bourdieu campos de dominación simbólica. Ambos, además, miraron con lucidez cuestiones ligadas a la dominación y reproducción de la dominación.

El autor señala una diferencia importante entre ellos, puntualmente sobre el rol social del intelectual y la distancia en torno a la idea de violencia simbólica de Bourdieu con el concepto de hegemonía de Gramsci. Para el francés, el intelectual debe mantener una distancia con el mundo social que es objeto de su estudio, mientras que para el italiano el intelectual deberá adoptar una postura orgánica con los intereses de clase que defiende. Por violencia simbólica Bourdieu dirá que es aquello que genera desconocimiento de la dominación como tal, en tanto que para Gramsci hegemonía implica un consentimiento consciente por la dominación. Gramsci admite el buen sentido dentro del sentido común de la clase trabajadora; para Bourdieu el sentido común era siempre un mal sentido.

En el capítulo 3, por medio de sus investigaciones etnográficas (1), Burawoy procura contrastar empíricamente la tesis de Gramsci en torno a la consciencia de dominación y la de Bourdieu sobre el desconocimiento de la dominación, reflexionando sobre la (falsa) conciencia de los trabajadores. Burawoy, que se reconoce gramsciano, coloca el concepto de hegemonía frente al de violencia simbólica de Bourdieu para evidenciar a limitación de ambos en las indagaciones sobre la clase obrera fabril, teniendo como referencia empírica sus estudios en los Estados Unidos, parte del occidente capitalista, y en Hungría, parte del bloque soviético. A partir de sus observaciones de las relaciones en los "regímenes despóticos de fábrica" dentro del socialismo real, el autor demuestra que allí la explotación a partir de la dominación es fácilmente verificable por la organización burocrática integral de la vida social que tenía el partido de gobierno. En este régimen de trabajo, las reglas de juego son arbitrarias e imposibilitan el establecimiento de procesos de consentimiento de dominación y explotación. Por otra parte, Burawoy menciona que los ambientes trabajo organizados en el capitalismo avanzado tienen condiciones más propicias para generar este consentimiento, ya que el ambiente de trabajo tiene relativamente autonomía, encubriendo la verdad objetiva del modo de producción capitalista: la explotación. Entonces, desde las observaciones realizadas, muestra la tendencia a una sumisión mayor a las instituciones del capitalismo avanzado que a las instituciones del socialismo real, fundamentando esto en la capacidad que el capitalismo avanzado tiene para generar consentimiento en la dominación. 
En el marco de estas reflexiones el autor marca un contrapunto con la teoría de Bourdieu, especialmente sobre los conceptos de dominación simbólica y habitus. Para él, estos conceptos no dan cuenta de las condiciones de explotación del trabajador en el capitalismo, uno de los ejes principales del análisis marxista: el primero de ellos, por no tener presente las condiciones institucionales de explotación y el segundo, porque considera que las disposiciones heredadas no son tan determinantes como Bourdieu afirmaba. Para Burawoy estas determinaciones tendrán un papel secundario frente a la intensidad incesante de las relaciones sociales, frente a la interacción generadora de contradicciones entre explotadores y explotados. Así, el habitus puede desempeñar un papel catalizador de la reproducción de la dominación pero también puede desempeñar un papel importante en la desarrollo de un nuevo orden social.

Cuando trata de relacionar a Bourdieu y Fanon, Burawoy trabaja sobre dos ejes. La distancia que hay entre origen social y académico de los dos autores y las distintas implicancias que ellos vivieron en el contexto de la Argelia colonial -y las batallas por su liberación- donde ambos tuvieron una experiencia intelectual y política.

El libro de Burawoy resalta la diferenciación de ambos con respecto a la cuestión colonial. Frente a eso Bourdieu ensaya una defensa de la posición ortodoxa marxista en lo que concierne al papel revolucionario de la clase obrera. Fanon, por otro lado, consideraba que ese papel histórico debería atribuírsele al campesinado. Igualmente, esta distancia no impidió que vieran al colonialismo como un sistema de dominación y expoliación en el que prevalecen múltiples violencias.

En el siguiente apartado, el autor plantea el diálogo de Bourdieu con Simone de Beauvoir. Allí muestra cómo el análisis de Bourdieu sobre la dominación masculina -entendida como violencia simbólica, inconsciente, como una denominación no reconocida como tal- se asemeja al planteo que hace Beauvoir en su famoso trabajo El Segundo Sexo (2), haciendo un Ilamado de atención sobre esto ya que subraya que en ningún momento el sociólogo aclara la influencia de la autora ni se muestra como deudor de su obra.

En el último capítulo tenemos el diálogo entre Pierre Bourdieu y Charles Wright Mills. Allí encontramos semejanzas entre los autores en sus recorridos de investigación, interesándose ambos sobre la comprensión de la Estructura Social, las clases sociales y las fracciones de clase, con especial énfasis en las elites y la forma en las que estas imponen y reproducen sus intereses particulares. Además, agrega Burawoy, tanto Bourdieu como Mills defienden la idea del intelectual como portador de una verdad científica.

En cuanto a las diferencias entre ellos, está tanto el contexto sociopolítico en el que cada uno escribe como la forma de abordar la dominación. Sobre esto último Burawoy distingue en la 
perspectiva de Mills una mirada, de reconocible influencia weberiana, vinculada a la concentración de recursos de poder; en tanto que para Bourdieu la dominación debe ser abordada de otra manera. Burawoy resalta aquí lo que es a su parecer la gran innovación de Bourdieu, esto es, el estudio de las dominación como parte de un dispositivo cultural de las elites y no solamente como una forma de una apropiación de recursos políticos, económicos y sociales.

Como hemos visto, en O Marxismo encontra Bourdieu Michael Burawoy propone una serie de diálogos, unos puentes levadizos de encuentros y desencuentros, entre un ícono de la sociología como Pierre Bourdieu y algunos autores marxistas. A quince años de su muerte, sin dudas Pierre Bourdieu se ha transformado en una figura intelectual canonizada, que suscita atención y respeto en el campo Ciencias Sociales. El libro de Michael Burawoy es un convite al encuentro de esta figura prestigiosa, tanto para conocedores como para quienes se estén iniciando en el estudio de la teoría social, para recorrer de modo claro tanto la obra de Bourdieu como el marxismo, al cual Burawoy adscribe, de forma no dogmática, para criticarlo y reivindicarlo a la vez.

\section{Notas}

(1) Burawoy, Michael (1985). The Politics of Production: Factory Regimes Under Capitalism and Socialism. London: Verso.

Burawoy, M. y Lukács, J. (1992). The Radiant Past: Ideology and Reality in Hungary's Road to Capitalism. Chicago: University of Chicago Press.

(2) De Beauvoir, Simone (2009). El segundo sexo. Argentina: Ed. Cúspide.

\section{Bibliografía}

Burawoy, M. (2010). O Marxismo encontra Bourdieu. Campinas, Brasil: Ed. Unicamp. 